\title{
Effects of surgery and radiofrequency ablation in the treatment of spinal metastases and analysis of the influencing factors of prognosis
}

\author{
MEILING LI $^{1}$, YAN ZHANG ${ }^{2}$ and XIUJUAN ZHANG ${ }^{2}$ \\ Departments of ${ }^{1}$ Gynecology and ${ }^{2}$ General Surgery, Weifang People's Hospital, Weifang, Shandong 261041, P.R. China
}

Received October 4, 2019; Accepted December 3, 2019

DOI: $10.3892 / \mathrm{etm} .2019 .8310$

\begin{abstract}
Effects of surgery and radiofrequency ablation in the treatment of spinal metastases were explored to analyze the influencing factors of prognosis. A total of 132 patients with spinal metastases admitted to Weifang People's Hospital were selected, 67 patients who underwent simple surgery were selected as the control group, and 65 patients who underwent radiofrequency ablation assisted surgery were the research group. The time of operation and intraoperative blood loss of patients in the two groups were recorded and compared. The visual analogue pain score (VAS), Karnofsky (KPS) score, Frankel spinal cord injury grading, and complications within 6 months after surgery were compared. The patients were followed up for 36 months and the survival rates were analyzed. Cox regression model was used to analyze the factors affecting the prognosis of patients. The time of operation and blood loss in the research group was significantly lower than that in the control group $(\mathrm{P}<0.05)$. The VAS, KPS scores, and Frankel grading of patients in the two groups after treatment were significantly improved compared with those before treatment, but the VAS and KPS scores of patients in the research group were significantly improved compared with those in the control group $(\mathrm{P}<0.05)$. The incidence rate of complications and 3-year recurrence rate in the research group were lower than those in the control group, and the 3 -year survival rate was significantly higher than that in the control group $(\mathrm{P}<0.05)$. The number of pathological cones, visceral metastasis, malignant degree, and radiofrequency ablation therapy are independent risk factors for poor prognosis of patients. Radiofrequency ablation assisted surgery can effectively improve the clinical efficacy of patients with spinal metastases, reduce postoperative complications and recurrence rate of patients, and prolong
\end{abstract}

Correspondence to: Dr Xiujuan Zhang, Department of General Surgery, Weifang People's Hospital, 151 Guangwen Street, Weifang, Shandong 261041, P.R. China

E-mail: xdn6xk@163.com

Key words: efficacy, influencing factors, prognosis, radiofrequency ablation, spinal metastatic tumor, surgery the survival time of patients compared with simple surgical treatment. It is worthy of clinical application.

\section{Introduction}

Spinal metastatic tumor is a common metastatic tumor of many advanced malignant tumors, which is mainly formed by the primary tumor transferring to the spine through blood or lymph metastasis (1). Spinal tumors are often characterized by multiple lesions involving multiple segments and accompanied by severe pain, which has a serious impact on the quality of life and health of patients (2). In the past, radiotherapy and chemotherapy as well as surgery were mainly used for the treatment of spinal metastases clinically. However, radiotherapy and chemotherapy for patients not only have a long treatment cycle, but also have many adverse reactions. Therefore, with the continuous development of medical technology in recent years, surgery has gradually become the main method for the treatment of spinal metastases. However, surgery still has the problems of large trauma, incomplete resection, and high recurrence rate $(3,4)$. Therefore, it is of great clinical significance to find a treatment method with better efficacy and less adverse effects for patients with spinal metastatic tumors (5).

Radiofrequency ablation is a tumor therapy method that has been gradually applied clinically in recent years. It mainly inactivates and damages tumor tissues of patients through friction heat generated by high-frequency current. It has the characteristics of less trauma and fewer complications (6). At present, radiofrequency ablation has achieved good efficacy in the treatment of various metastatic tumors such as bone metastasis of breast cancer (7), liver metastasis of rectal cancer (8), and the combination of surgery. There is also research (9) showing that patients with spinal metastases have achieved 89 and $70 \%$ local control, respectively, in 3 months and 1 year after percutaneous radiofrequency ablation.

Although some studies have been reported on the application of radiofrequency ablation in spinal metastatic tumors, few studies have been carried out to analyze the effects of radiofrequency ablation and the influencing factors on the prognosis of patients. Therefore, in this study, the effects of radiofrequency ablation assisted with traditional open surgery in spinal metastatic tumors and the influencing factors on the prognosis of patients, were analyzed with a view to provide 
more basis for clinical treatment of patients with spinal metastatic tumors.

\section{Materials and methods}

General data. A total of 132 patients with spinal metastases from April 2014 to February 2016 were selected, including 71 male and 61 female patients. Their average age was $57.64 \pm 10.29$. The patients were divided into research group and control group according to the treatment plan accepted by the patients. Sixty-seven patients with simple surgery were regarded as the control group, and 65 patients with radiofrequency ablation assisted surgery were the research group. Inclusion exclusion criteria were as follows: Inclusion criteria were as follows: Patients diagnosed as spinal metastases by pathological diagnosis, patients who have undergone primary tumor resection, patients with an expected survival period of more than 6 months, and patients with preoperative tolerance to surgery. Exclusion criteria were as follows: Patients with contraindications to surgery, patients with unclear primary focus, patients with severe liver and kidney dysfunction, patients with unclear surgical indications, patients with serious heart and lung diseases, patients who did not cooperate with the study, patients with communication or cognitive impairment. All patients and their families agreed to participate in the experiment and sign an informed consent. The study was approved by the Ethics Committee of Weifang People's Hospital (Weifang, China).

Treatment methods. All patients underwent imaging examination before surgery to determine the location and number of lesions and cones, and the degree of cone deterioration and spinal cord compression were evaluated. The patients in the control group were treated with simple open cone resection. After general anesthesia, the patients were placed in prone position. The pathological cones located before surgery were taken as the center to make a longitudinal incision. The upper and lower cones of the pathological cones were fixed and the muscles beside the cones were separated. First, accessory tumors such as vertebral pedicle or lamina were excised. Then, unilateral laminectomy and decompression were performed. In addition, tumor tissues that compressed spinal cord in spinal canal were excised. In order to better perform bone graft fusion, during the resection of the affected cone, attention should also be paid to the removal of its corresponding upper and lower intervertebral discs. After the resection was completed, bone cement was poured into the resection site. The resection site was filled with bone cement. After the bone cement was solidified, the bone threading needle was pulled out and the operation area was sterilized and flushed. The drainage tube was placed for negative pressure drainage. Finally, the incision was closed. Patients in the research group were assisted with radiofrequency ablation on the basis of patients in the control group. After cone resection, UniBlate monopolar needle electrode (RITA1500X type) was introduced into the pathological cones through vertebral pedicle under X-ray fluoroscopy, and the initial power was set at $150 \mathrm{~W}$. The ablation range was set according to the tumor and the pathological degree. The temperature of the radiofrequency needle was controlled at $80-100^{\circ} \mathrm{C}$. The time of single point ablation is $6-12 \mathrm{~min}$.
During ablation, the blood loss and changes of vital signs of patients were closely detected. The ablation area was appropriately expanded to $0.5 \mathrm{~cm}$ beyond the edge of the lesions. Bone cement was injected after ablation. The method was the same as that of the control group. All patients were treated with cefradine ( $2 \mathrm{~g} / 12 \mathrm{~h}$ ) for 3 days after surgery.

Observation indicators. i) The time of operation and intraoperative blood loss of patients in the two groups were recorded and compared. ii) Visual analogue pain score (VAS) (10) was evaluated before and 6 months after surgery of patients in both groups. iii) The Karnofsky (KPS) (11) scores before and 6 months after surgery of patients in the two groups were compared.iv) The Frankel spinal cord injury grading (12) before and 6 months after surgery of patients in the two groups were compared. v) The complications of patients in the two groups within 6 months after surgery were recorded and compared. The complications included bone cement leakage, hemorrhage, deep venous thrombosis of lower limbs, and infection. vi) The patients were followed up for 36 months and the survival rates of the two groups were analyzed. vii) Cox regression model was used to analyze the factors affecting the prognosis of patients.

Statistical methods. In this study, the experimental data were statistically analyzed by SPSS 18.0 software. The counting data adopted Chi-square test, and the measurement data adopted mean \pm standard deviation. The comparison between the two groups adopted t test. The experimental images were drawn by GraphPad Prism 6, correlation analysis was by Pearson's, survival analysis used Kaplan-Meier survival curve, multivariate analysis of prognostic risk factors of patients adopted Cox regression model. $\mathrm{P}<0.05$ was considered to indicate a statistically significant difference.

\section{Results}

Comparison of general data. There was no significant difference in sex, age, number of pathological cones, and nerve involvement of patients between the two groups $(\mathrm{P}>0.05)$ (Table I).

\section{Comparison of time of operation and intraoperative blood} loss of patients between the two groups. The time of operation and intraoperative blood loss of patients in the research group were $211.13 \pm 31.48 \mathrm{~min}$ and $1026.72 \pm 316.97 \mathrm{ml}$, respectively, while the time of operation and intraoperative blood loss of patients in the control group were $302.26 \pm 46.75 \mathrm{~min}$ and $1603.95 \pm 427.51 \mathrm{ml}$, respectively. The time of operation and intraoperative blood loss of patients in the research group were significantly lower than those in the control group, with statistically significant difference $(\mathrm{P}<0.05)$ (Fig. 1).

VAS and KPS scores of patients in the two groups before and after treatment. The VAS and KPS scores of patients in the two groups before treatment were not significantly different $(\mathrm{P}>0.05)$. The VAS scores of patients in the two groups after treatment were lower than those before treatment, and KPS scores were significantly higher than those before treatment. However, the improvement of patients in the research group was more obvious than that in the control group, and the difference was statistically significant $(\mathrm{P}<0.05)$ (Fig. 2). 
Table I. General data.

\begin{tabular}{|c|c|c|c|c|}
\hline Factors & Research group $n=65$ & Control group $n=67$ & $\mathrm{t} / \chi^{2}$ value & P-value \\
\hline Sex & & & 0.131 & 0.717 \\
\hline Male & $36(55.38)$ & $35(52.24)$ & & \\
\hline Female & $29(44.61)$ & $32(47.76)$ & & \\
\hline Age (years) & $56.07 \pm 10.11$ & $57.12 \pm 9.85$ & 0.547 & 0.604 \\
\hline $\operatorname{BMI}\left(\mathrm{kg} / \mathrm{m}^{2}\right)$ & $22.54 \pm 1.48$ & $22.37 \pm 1.52$ & 0.651 & 0.516 \\
\hline Number of pathological cones & & & 0.270 & 0.966 \\
\hline 1 segment & $36(55.38)$ & $39(58.21)$ & & \\
\hline 2 segments & $13(20.22)$ & $14(20.90)$ & & \\
\hline 3 segments & $10(15.38)$ & $9(13.43)$ & & \\
\hline 4 segments & $6(9.23)$ & $5(7.46)$ & & \\
\hline Nerve involvement & & & 0.032 & 0.858 \\
\hline Yes & $31(47.69)$ & $33(49.25)$ & & \\
\hline No & $34(52.31)$ & $34(50.75)$ & & \\
\hline Malignant degree & & & 0.280 & 0.869 \\
\hline High & $20(30.77)$ & $21(31.34)$ & & \\
\hline Moderate & $30(46.15)$ & $33(49.25)$ & & \\
\hline Low & $15(23.08)$ & $13(19.40)$ & & \\
\hline
\end{tabular}
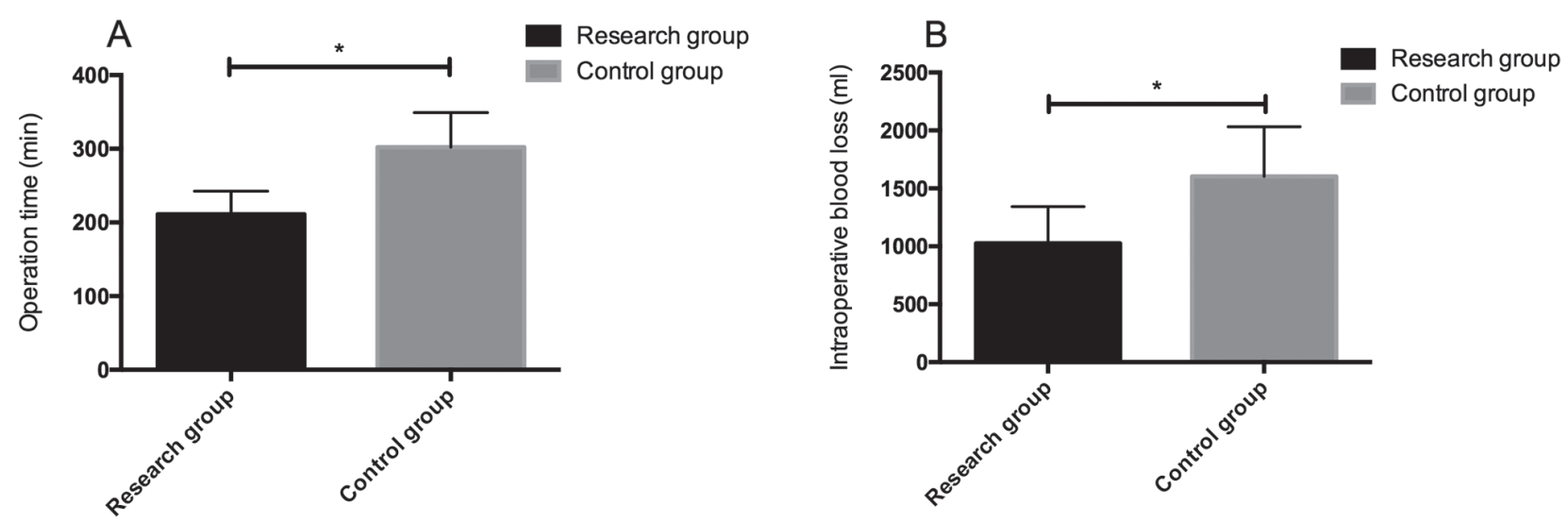

Figure 1. Comparison of time of operation and intraoperative blood loss of patients between the two groups. (A) The time of operation of patients in the research group is significantly lower than that of patients in the control group. (B) The intraoperative blood loss of patients in the research group is significantly lower than that of patients in the control group. ${ }^{*} \mathrm{P}<0.05$.

Frankel spinal cord injury grading of patients in the two groups before and after treatment. There was no significant difference in Frankel grading of patients between the two groups before treatment $(\mathrm{P}>0.05)$. Frankel grading of patients in the two groups after treatment was significantly improved compared with that before treatment $(\mathrm{P}<0.05)$. There was no significant difference in Frankel grading after improvement between the two groups $(\mathrm{P}>0.05)$ (Table II).

Complications of patients in the two groups. The number of patients in the research group with leakage, hemorrhage, deep venous thrombosis of lower limbs, and infection was 2 , 1,1 , and 1 , respectively, with a complication rate of $7.69 \%$. The number of patients in the control group with leakage, hemorrhage, deep venous thrombosis, and infection was $4,2,2$, and 3 , respectively, with a complication rate of
$19.40 \%$. In addition, the complication rate of patients in the research group was significantly lower than that of patients in the control group, with statistically significant difference $(\mathrm{P}<0.05)$ (Table III).

Comparison of recurrence rate and survival rate of patients between the two groups. During the 36-month follow-up period, there were no patients who missed the visit. There were 40 patients in the research group who relapsed, with a recurrence rate of $61.54 \%$ in 3 years, and 39 patients died, with a 3 -year survival rate of $40.00 \%(26 / 65)$. There were 55 patients in the control group who relapsed, with a recurrence rate of $82.09 \%$ in 3 years, and 49 patients died, with a 3 -year survival rate of $28.36 \%$ (19/67). The 3 -year recurrence rate of patients in the research group was significantly lower than that in the control group, and the survival rate 

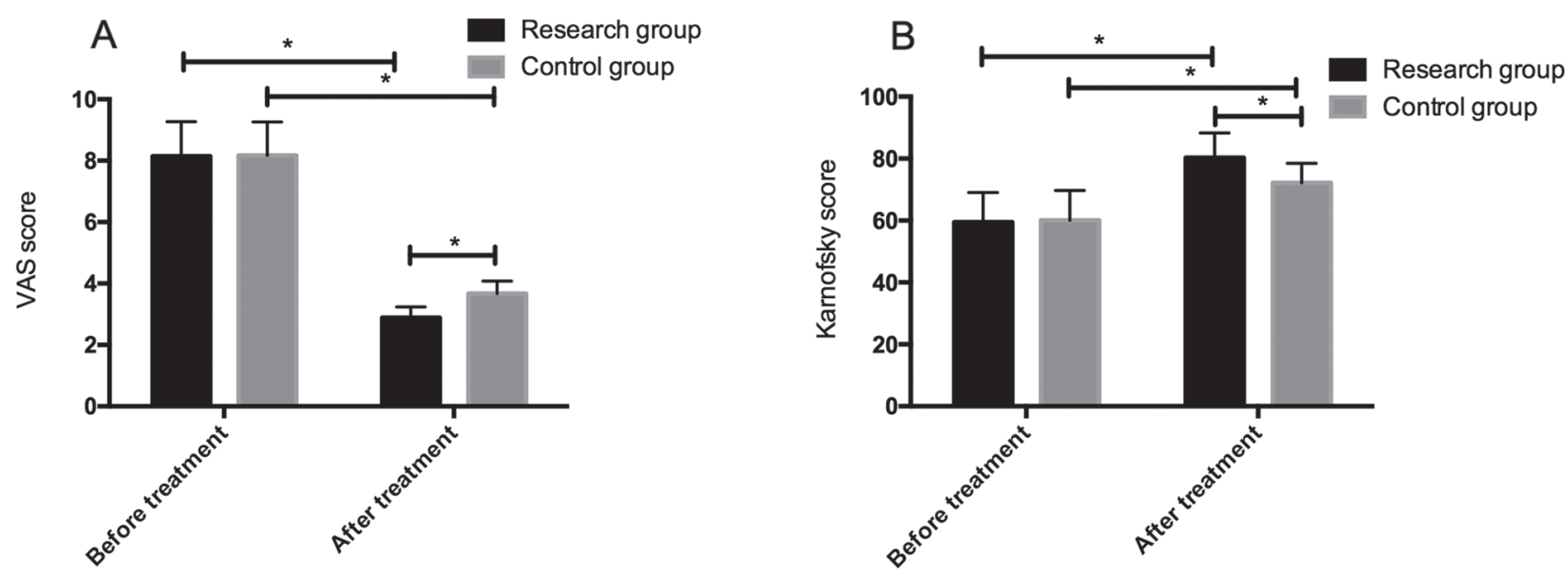

Figure 2. VAS and Karnofsky scores of patients in the two groups before and after treatment. (A) VAS scores of patients in the two groups decreased after treatment compared with before treatment, but the improvement of patients in the research group was more obvious than that in the control group. (B) Karnofsky scores of patients in the two groups after treatment were significantly higher than those before treatment, but the improvement of patients in the research group was more obvious than that in the control group. "P<0.05. VAS, visual analogue pain score.

Table II. Frankel spinal cord injury grading of patients in the two groups before and after treatment.

\begin{tabular}{|c|c|c|c|c|c|c|c|c|c|c|c|c|}
\hline \multirow[b]{2}{*}{ Grouping } & \multicolumn{5}{|c|}{ Before treatment } & \multicolumn{5}{|c|}{ After treatment } & \multirow[b]{2}{*}{$\chi^{2}$ value } & \multirow[b]{2}{*}{ P-value } \\
\hline & A & B & $\mathrm{C}$ & $\mathrm{D}$ & $\mathrm{E}$ & A & B & $\mathrm{C}$ & $\mathrm{D}$ & $\mathrm{E}$ & & \\
\hline $\begin{array}{l}\text { Research } \\
\text { group } n=65\end{array}$ & 0 & $\begin{array}{c}10 \\
(15.38)\end{array}$ & $\begin{array}{c}36 \\
(55.38)\end{array}$ & $\begin{array}{c}19 \\
(29.23)\end{array}$ & 0 & 0 & $\begin{array}{c}5 \\
(7.69)\end{array}$ & $\begin{array}{c}27 \\
(41.54)\end{array}$ & $\begin{array}{c}26 \\
(40.00)\end{array}$ & $\begin{array}{c}7 \\
(10.77)\end{array}$ & 11.04 & 0.012 \\
\hline $\begin{array}{l}\text { Control } \\
\text { group } n=67\end{array}$ & 0 & $\begin{array}{c}11 \\
(16.42)\end{array}$ & $\begin{array}{c}36 \\
(53.73)\end{array}$ & $\begin{array}{c}20 \\
(29.85\end{array}$ & 0 & 0 & $\begin{array}{c}9 \\
(13.43)\end{array}$ & $\begin{array}{c}27 \\
(40.30)\end{array}$ & $\begin{array}{c}25 \\
(37.31)\end{array}$ & $\begin{array}{c}6 \\
(8.96)\end{array}$ & 8.041 & 0.045 \\
\hline$\chi^{2}$ value & & & 0.043 & & & & & 1.209 & & & & \\
\hline P-value & & & 0.979 & & & & & 0.751 & & & & \\
\hline
\end{tabular}

Table III. Complications of patients in the two groups.

\begin{tabular}{lcccc}
\hline Factors & Research group $n=65$ & Control group $n=67$ & $\chi^{2}$ value & P-value \\
\hline Leakage & $2(3.08)$ & $6(8.96)$ & 2.002 & 0.157 \\
Hemorrhage & $1(1.54)$ & $2(2.99)$ & 0.311 & 0.577 \\
Deep venous thrombosis of lower limbs & $1(1.54)$ & $2(2.99)$ & 0.311 & 0.577 \\
Infection & 0 & $3(4.48)$ & 2.978 & 0.084 \\
Total incidence rate & $4(7.69)$ & $13(19.40)$ & 5.162 & 0.023 \\
\hline
\end{tabular}

was significantly higher than that in the control group, with statistically significant difference $(\mathrm{P}<0.05)$ (Fig. 3).

Single analysis of poor prognosis in patients with spinal metastasis tumor. We divided patients into death group (88 cases) and survival group (44 cases) according to their 3-year survival conditions. We analyzed the clinical and pathological data of patients in the two groups. The results showed that the number of pathological cones, visceral metastasis, nerve involvement, malignant degree, and radiofrequency ablation treatment may be the factors affecting the poor prognosis of patients $(\mathrm{P}<0.05)$ (Table IV).
Multivariate analysis of poor prognosis in patients with spinal metastasis tumor. Through single factor analysis, we found that the number of pathological cones, visceral metastasis, nerve involvement, malignant degree, and radiofrequency ablation therapy might be factors that affect the poor prognosis of patients. Then we assigned values to the single factors that have differences (Table V) and further included the single factors that have differences into Cox risk proportion model for analysis. The results showed that the number of pathological cones, visceral metastasis, malignant degree, and radiofrequency ablation therapy were independent risk 
Table IV. Single analysis of poor prognosis in patients with spinal metastasis tumor.

\begin{tabular}{|c|c|c|c|c|}
\hline Factors & Survival group $n=44$ & Death group $n=88$ & $\mathrm{t} / \chi^{2}$ value & P-value \\
\hline Sex & & & 0.061 & 0.805 \\
\hline Male & $21(47.73)$ & $40(45.45)$ & & \\
\hline Female & $23(52.27)$ & $48(54.55)$ & & \\
\hline Age (years) & $57.15 \pm 9.27$ & $56.42 \pm 9.68$ & 0.414 & 0.679 \\
\hline Number of pathological cones & & & 18.71 & $<0.001$ \\
\hline 1 segment & $36(81.82)$ & $39(44.32)$ & & \\
\hline 2 segments & $6(13.64)$ & $21(23.86)$ & & \\
\hline 3 segments & $2(4.54)$ & 17 (19.32) & & \\
\hline 4 segments & 0 & $11(12.51)$ & & \\
\hline Visceral metastasis & & & 7.443 & 0.006 \\
\hline Yes & $12(27.27)$ & $46(52.27)$ & & \\
\hline No & $32(72.73)$ & $42(47.73)$ & & \\
\hline Nerve involvement & & & 5.475 & 0.019 \\
\hline Yes & $15(34.09)$ & $49(55.68)$ & & \\
\hline No & $23(52.27)$ & $39(44.32)$ & & \\
\hline Malignant degree & & & 10.74 & 0.005 \\
\hline High & $8(18.18)$ & $33(37.50)$ & & \\
\hline Moderate & $20(45.45)$ & $43(48.86)$ & & \\
\hline Low & $16(36.36)$ & $12(13.64)$ & & \\
\hline Radiofrequency ablation therapy & & & 11.88 & $<0.001$ \\
\hline Yes & $31(70.45)$ & $34(38.64)$ & & \\
\hline No & $13(29.55)$ & $54(61.36)$ & & \\
\hline
\end{tabular}

Table V. Assignments.

\begin{tabular}{ll}
\hline Factors & \multicolumn{1}{c}{ Assignment } \\
\hline No. of pathological cones & $\begin{array}{l}\text { 1 segment=1, 2 segments=2, } \\
3 \text { segments=3, 4 segments=4 }\end{array}$ \\
Visceral metastasis & Not transferred=1, transferred=2 \\
Malignant degree & Low=1, moderate=2, high=3 \\
Radiofrequency ablation & Yes=1, no=2 \\
Nerve involvement & No=1, yes=2 \\
Living conditions & Survival=1, death=2 \\
\hline
\end{tabular}

factors that affect the poor prognosis of patients. More details are shown in Table VI.

\section{Discussion}

Spine is a high incidence site for malignant tumor metastases. Spinal metastatic tumors will lead to intractable pain and nerve compression and other symptoms, which will have a serious impact on the quality of life of patients (13). At present, the treatment of spinal metastases mainly focuses on nerve compression of patients and pain relief. In the past, conservative methods such as radiotherapy, chemotherapy, and palliative treatment were mainly adopted to treat spinal metastases, but the efficacy was not good (14). Therefore, it is

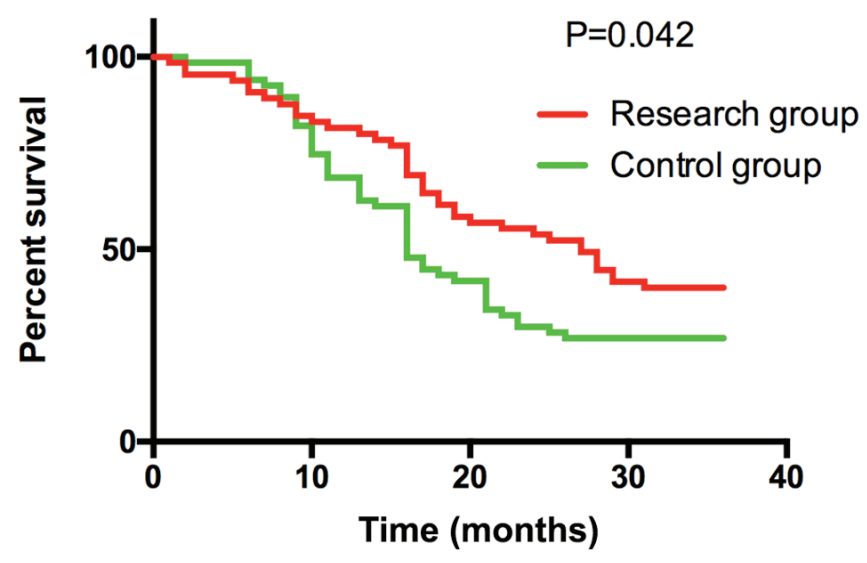

Figure 3. Comparison of 3-year survival rate of patients between the two groups. The 3 -year survival rate of patients in the research group is significantly higher than that of patients in the control group.

of great clinical significance to find a treatment method with better efficacy for patients with spinal metastases.

In the present study, we analyzed the clinical efficacy of simple surgery and radiofrequency ablation assisted surgery in the treatment of spinal metastases and the impact on the prognosis of patients. This research was carried out due to the continuous development of surgical techniques in recent years, and surgery has gradually become the main method for the treatment of spinal metastases (15). Previous studies (16) 
Table VI. Multivariate analysis of poor prognosis in patients with spinal metastasis tumor.

\begin{tabular}{lcccccc}
\hline Independent variable & $\beta$ & SE & Wald & P-value & OR & $95 \%$ CI \\
\hline No. of pathological cones & 1.171 & 0.482 & 5.543 & 0.014 & 3.229 & $2.819-7.531$ \\
Visceral metastasis & 1.085 & 0.544 & 11.176 & 0.001 & 6.082 & $1.085-8.039$ \\
Malignant degree & 1.077 & 0.536 & 11.168 & 0.001 & 6.084 & $1.076-8.031$ \\
Radiofrequency ablation & 1.238 & 0.455 & 7.208 & 0.004 & 3.452 & $2.117-7.307$ \\
Nerve involvement & 0.927 & 1.169 & 0.624 & 0.472 & - & - \\
\hline
\end{tabular}

have shown that surgical treatment can better improve the neurological function of patients with spinal metastases, and it is considered to be superior to radiotherapy and chemotherapy in relieving pain of patients. However, simple cone resection not only has great trauma to the patients, but also leads to a higher recurrence rate for some tumors that are difficult to be excised (17). Radiofrequency ablation is a thermal ablation technique gradually applied in tumor treatment in recent years, and friction heat can be generated by alternating current, so as to perform targeted ablation on tumors, which is beneficial to local control of metastatic lesions (18). The results of our study show that the time of operation and intraoperative blood loss of patients in the research group are significantly lower than those in the control group, which suggests that we can effectively reduce the time of operation and blood loss when radiofrequency ablation is used to assist surgery.

Previous studies $(19,20)$ have shown that one of the advantages of radiofrequency ablation is that it can coagulate tumor microvessels locally through thermal ablation, which is conducive to reducing the density of blood vessels and the amount of bleeding during surgery, and is also conducive to surgical operation so as to shorten the time of operation, which proves and explains our results. Then the VAS, KPS scores, and Frankel grading of patients in the two groups before and after surgery were compared. The results showed that the VAS, KPS scores, and Frankel grading of patients in the two groups after treatment were significantly improved compared with those before treatment. However, the VAS and KPS scores of patients in the research group were more improved than those in the control group, and there was no significant difference in the improved number of Frankel grading. This suggests that surgery has a good effect on the neurological function recovery of patients with spinal metastases, but if assisted with radiofrequency ablation, it can more effectively relieve pain of patients and promote the functional recovery of patients.

Previous research (18) have indicated that when radiofrequency ablation and surgery are combined, radiofrequency ablation can create ablation gaps in the pathological cones, which is conducive to the injection of bone cement and the reduction of leakage rate, thus relieving the pain of patients. In addition, there is also research (21) showing that the pain relief rate for patients with spinal metastases can reach $100 \%$ when radiofrequency ablation and surgery are combined. This is consistent with our conclusion. The complications and 3-year survival rate of patients in the two groups were compared. The results showed that the incidence rate of complications of patients in the research group was significantly lower than that of the control group, and the 3-year recurrence rate was significantly lower than that of the control group. The 3-year survival rate was significantly higher than that of the control group. This suggests that the application of radiofrequency ablation in the surgical operation of spinal metastases is beneficial to reduce the occurrence of postoperative complications and tumor recurrence and prolong the survival time of the patients. Previous research (22) have indicated that radiofrequency ablation can directly act on the tumor itself, and ablation technology can cause coagulation necrosis of the tumor, which can enhance the efficacy of the surgery and reduce recurrence.

For a long time, the prognosis of spinal metastases has been a difficult clinical problem. Although we found in previous studies that the use of radiofrequency ablation may affect the prognosis of patients, it still needs further confirmation in subsequent experiments. Therefore, we analyzed the factors that affected the prognosis of patients with spinal metastases. The results showed that the number of pathological cones, visceral metastasis, malignant degree, and radiofrequency ablation therapy were independent risk factors that affected the prognosis of patients with spinal metastases. Previous studies (23) have indicated that the malignant degree of the tumor itself will have a direct impact on the prognosis of patients. There is also research (24) that organ metastasis of tumor is an important factor affecting poor prognosis of tumor patients. Moreover, for patients with spinal metastases, a larger number of cones means a greater treatment risk and a longer postoperative recovery time, which will also have an important impact on the prognosis of patients (25). However, radiofrequency ablation is proposed for the first time in our study as a protective factor for the prognosis of patients with spinal metastases, which needs further research in the future.

Collectively, radiofrequency ablation assisted surgery can effectively improve the clinical efficacy of patients with spinal metastases, reduce the postoperative complications and recurrence rate of patients, and prolong the survival time of patients compared with simple surgical treatment. Moreover, the malignant degree of tumors, the presence or absence of organ metastasis and the number of pathological cones are independent risk factors leading to poor prognosis of patients. The application of radiofrequency ablation is a protective factor for the prognosis of patients. In our opinion, patients conforming to the principles of surgical treatment should be recommended the use of radiofrequency ablation assisted surgery.

\section{Acknowledgements}

Not applicable. 


\section{Funding}

No funding was received.

\section{Availability of data and materials}

The datasets used and/or analyzed during the current study are available from the corresponding author on reasonable request.

\section{Authors' contributions}

ML observed indicators and wrote the manuscript, interpreted and analyzed the data. YZ designed the study and performed the experiment. $\mathrm{XZ}$ was responsible for the analysis and discussion of the data. All authors read and approved the final manuscript.

\section{Ethics approval and consent to participate}

The study was approved by the Ethics Committee of Weifang People's Hospital (Weifang, China). Patients who participated in this research had complete clinical data. Signed informed consents were obtained from the patients and/or the guardians.

\section{Patient consent for publication}

Not applicable.

\section{Competing interests}

The authors declare that they have no competing interests.

\section{References}

1. Wang J, Fang Z, Lang N, Yuan H, Su MY and Baldi P: A multiresolution approach for spinal metastasis detection using deep Siamese neural networks. Comput Biol Med 84: 137-146, 2017.

2. Roser S, Maharaj MM, Taylor MA, Kuru R, Hansen MA and Ferch R: Vertebrectomy in metastatic spinal tumours: A 10 year, single-centre review of outcomes and survival. J Clin Neurosci 68: 218-223, 2019

3. Gharzai LA, Beeler WH, Hayman JA, Mancini B, Jagsi R, Pierce L, Moran JM, Dominello MM, Boike T, Griffith K, et al, Michigan Radiation Oncology Quality Consortium: Recommendations for single faction radiation therapy and stereotactic body radiation therapy in palliative treatment of bone metastases: A statewide practice patterns survey. Pract Radiat Oncol 9: e541e548, 2019 .

4. Pennington Z, Ahmed AK, Cottrill E, Westbroek EM, Goodwin ML and Sciubba DM: Intra- and interobserver reliability of the Spinal Instability Neoplastic Score system for instability in spine metastases: A systematic review and metaanalysis. Ann Transl Med 7: 218, 2019.

5. Schaub SK, Tseng YD, Chang EL, Sahgal A, Saigal R, Hofstetter CP, Foote M, Ko AL, Yuh WTC, Mossa-Basha M, et al: Strategies to mitigate toxicities from stereotactic body radiation therapy for spine metastases. Neurosurgery 85: 729-740, 2019.

6. Zhang Y, Zhang MB, Luo YK, Li J, Zhang Y and Tang J: Effect of chronic lymphocytic thyroiditis on the efficacy and safety of ultrasound-guided radiofrequency ablation for papillary thyroid microcarcinoma. Cancer Med 8: 5450-5458, 2019.

7. Leto G: Current status and future directions in the treatment of bone metastases from breast cancer. Clin Exp Pharmacol Physiol 46: 968-971, 2019.
8. van Amerongen MJ, van der Stok EP, Fütterer JJ, Jenniskens SFM, Moelker A, Verhoef C, Grünhagen DJ and de Wilt JHW: Results after simultaneous surgery and RFA liver ablation for patients with colorectal carcinoma and synchronous liver metastases. Eur J Surg Oncol: Jul 7, 2019 (Epub ahead of print).

9. Wallace AN, Tomasian A, Vaswani D, Vyhmeister R, Chang RO and Jennings JW: Radiographic local control of spinal metastases with percutaneous radiofrequency ablation and vertebral augmentation. AJNR Am J Neuroradiol 37: 759-765, 2016.

10. Cooke ME, Welch T, Gusakov O and Tornetta P III: Are continuous femoral nerve catheters beneficial for pain management after operative fixation of tibial plateau fractures? A randomized controlled trial. J Orthop Trauma 33: e447-e451, 2019.

11. Barbetta C, Allgar V, Maddocks M, Ribeiro C, Wilcock A, Currow DC, Phillips J and Johnson MJ: Australia-modified Karnofsky Performance Scale and physical activity in COPD and lung cancer: An exploratory pooled data analysis. BMJ Support Palliat Care: Jul 11, 2019 (Epub ahead of print).

12. Capaul M, Zollinger H, Satz N, Dietz V, Lehmann D and Schurch B: Analyses of 94 consecutive spinal cord injury patients using ASIA definition and modified Frankel score classification. Paraplegia 32: 583-587, 1994.

13. Buergy D, Sharfo AW, Heijmen BJ, Voet PW, Breedveld S, Wenz F, Lohr F and Stieler F: Fully automated treatment planning of spinal metastases - A comparison to manual planning of Volumetric Modulated Arc Therapy for conventionally fractionated irradiation. Radiat Oncol 12: 33, 2017.

14. Hamad A, Vachtsevanos L, Cattell A, Ockendon M and Balain B: Minimally invasive spinal surgery for the management of symptomatic spinal metastasis. Br J Neurosurg 31: 526-530, 2017.

15. Guzik G: Oncological and functional results of the surgical treatment of vertebral metastases in patients with multiple myeloma. BMC Surg 17: 92, 2017.

16. Patchell RA, Tibbs PA, Regine WF, Payne R, Saris S, Kryscio RJ, Mohiuddin M and Young B: Direct decompressive surgical resection in the treatment of spinal cord compression caused by metastatic cancer: A randomised trial. Lancet 366: 643-648, 2005.

17. de Ruiter GC, Nogarede CO, Wolfs JF and Arts MP: Quality of life after different surgical procedures for the treatment of spinal metastases: Results of a single-center prospective case series. Neurosurg Focus 42: E17, 2017.

18. Kam NM, Maingard J, Kok HK, Ranatunga D, Brooks D, Torreggiani WC, Munk PL, Lee MJ, Chandra RV and Asadi H: Combined vertebral augmentation and radiofrequency ablation in the management of spinal metastases: An update. Curr Treat Options Oncol 18: 74, 2017.

19. Griessenauer CJ, Salem M, Hendrix P, Foreman PM, Ogilvy CS and Thomas AJ: Preoperative embolization of spinal tumors: A systematic review and meta-analysis. World Neurosurg 87: 362-371, 2016.

20. Stephenson MB, Glaenzer B and Malamis A: Percutaneous minimally invasive techniques in the treatment of spinal metastases. Curr Treat Options Oncol 17: 56, 2016.

21. Toyota N, Naito A, Kakizawa H, Hieda M, Hirai N, Tachikake T, Kimura T, Fukuda $\mathrm{H}$ and Ito K: Radiofrequency ablation therapy combined with cementoplasty for painful bone metastases: Initial experience. Cardiovasc Intervent Radiol 28: 578-583, 2005.

22. Wang GW, Han XX, Ma YL, Duo J, Yang JL and Liao ZC: Radiofrequency ablation combined with subtotal corpectomy for spinal metastases. Chin J Orthop 31: 938-943, 2011 (In Chinese).

23. Hu H, Yang HL, Wang GL, Chen KW, Zhou QS and Zhou M: The decision-making and survival prediction role of Tomita score in the management spinal metastases. Chin J Spin Spin Cord 22: 673-677, 2012 (In Chinese).

24. Hibberd CS and Quan GMY: Accuracy of preoperative scoring systems for the prognostication and treatment of patients with spinal metastases. Int Sch Res Notices 2017: 1320684, 2017.

25. Pointillart V, Vital JM, Salmi R, Diallo A and Quan GM: Survival prognostic factors and clinical outcomes in patients with spinal metastases. J Cancer Res Clin Oncol 137: 849-856, 2011.

(i) $\Theta($ This work is licensed under a Creative Commons

Attribution-NonCommercial-NoDerivatives 4.0 International (CC BY-NC-ND 4.0) License. 